\title{
THE GENERATIVE SIMILARITIES OF DESIGNS, PROTOTYPES, AND SCENARIOS
}

\author{
Celso Carnos Scaletsky ${ }^{1}$ \\ Unisinos \\ celsocs@unisinos.br \\ Stanley Ruecker \\ Institute of Design - Illinois Institute of Technology \\ sruecker@id.iit.edu \\ Santosh Basapur \\ Institute of Design - Illinois Institute of Technology \\ basapur@id.iit.edu
}

\begin{abstract}
In this paper, we discuss the conceptual and practical relationships of three common products of design and design research: designs, prototypes, and scenarios. In addition, we examine the related actions of designing, prototyping, and writing scenarios. We suggest that rather than accepting the common understanding of these three artifacts and processes as distinct phenomena, it is useful to consider them as three aspects of a larger construct that is characterized by features such as invention, meaning-making, reification of ideas, and mediation among interlocutors. This interpretation has consequences for our understanding of these artifacts and processes, both as potential means of knowledge production, and as attempts to define our disciplinary boundaries, suggesting that a relatively small shift in design practice could produce significant benefits for the field as a whole.
\end{abstract}

Keywords: Designs, Prototype, Scenario, Mediation. 


\section{INTRODUCTION}

Design research, after 50 years, is still seeking a better definition of its borders in order to consolidate itself as a field of knowledge. Borders can often be simple spaces of exchange, transition, and learning, but they can also serve as barriers or walls. When this happens, often rather than growth one can obtain isolation, creating niches and feuds that can be harmful to the idea of growing. The area also runs the risk of becoming incomprehensible to the rest of the academic community. This article proposes an inversion vision for some important issues of Design. Contrary to putting design as a higher element of a hierarchy, we propose that design can be understood as a result of some processes that go beyond its borders. The intent is to propose a practical means of expansion of the scope of the design concept, bringing it more in line with aspirations of decades past.

In this formulation, between a present situation and a desired future state, invention is placed at the highest level of acts that generate artifacts. This is based on the assumption that inventing is a creative human activity, as an articulation of existing knowledge with the construction of the new. To invent we construct models and simulations of possible worlds. These, in turn, may be associated with the concepts of scenarios and prototypes, as a special kind of models that seek to simulate inventions. All these processes are typical of human reasoning and are used in the act of designing, but they also extend far beyond the borders of the discipline. To extend our reach, we therefore propose that design as a field make increased efforts to focus attention on the versions of these activities that can help to form a body of designspecific knowledge.

\section{DESIGNS}

In this work we use the word designs to mean the outcomes of designing: artifacts in the broad sense that includes services, experiences, environments, and so on. We also use the concept of Design as a process: to design is to project in time, to throw yourself forward. It can be interpreted as the act of building artifacts that do not (yet) exist. Designing also involves taking risks, working with the unpredictable. When people jump off a cliff in performing the activity called "base jumping" just using some fabrics or plastics to literally fly, they usually know about the technical aspects of this activity. Many will have practiced this sport countless times, studied the weather and geography of the place. However, in a few seconds, someone who has jumped will have to live with environmental factors that arise unexpected (e.g. a wind gust or a bush not observed) and will have to make decisions in tenths of a second. The act of designing, also, coexists with the search for objectives and prior information, as well as the construction of knowledge in the problematic situation, at the moment. In the "design game", the designer should articulate moments where decision-making involves more or fewer certain elements. So the first feature of designing is to be at once both planned and situational.

The metaphor of building the path by walking it strengthens the nonlinear and dynamic aspect of the process. This is not a simple process of analysis and synthesis, although certainly it involves these two moments. As an activity that involves creativity, designers build associations with elements that they have lived (experience) with context factors and thus, generate new ideas. This is the abductive character of 
the design process. In much of the process designers avoid working with absolutes, yes or no or even 0 or 1 . The expression "if then" well characterizes the importance of generating hypotheses to be tested. One of the complexities of the process refers to its open nature where several hypotheses are equally valid. How to choose the path to follow? And what to do when this path looks inappropriate or apparently less appropriate than the previously formulated ideas? Thus, one can identify the third characteristic that defines the act of designing: as a learning process. In this paper, learning is associated with the construction of knowledge. When designers create sketches, texts, and do research they are producing a kind of knowledge in a broad sense of the word. Designing knowledge refers to building something that did not exist before the process starts. This knowledge differs from scientific knowledge that can be validated, questioned and replicated in other situations. The knowledge generated in a project can be frequently only relevant to the specific project situation. However, when building something that did not exist and thus generating knowledge, one is experiencing a process of learning. This learning will be reflected in the designer experience and could be the base for new projects.

This particular type of knowledge we will call design knowledge. It is often associated with the "trial and error" process, the error leading to new knowledge, as in any learning process. When we go back and redo a path we are not the same. For this reason, several models that seek to represent the path of creating a project use the metaphor of the spiral. A spiral has an upward path toward an answer (or many answers) for a given situation. The number of upward cycles is related to the number of past steps. However, the process is more complex because it is not necessarily continuous. The process of trial and error passes through prototyping. What is the concept and role of prototyping in this complex system?

\section{PROTOTYPING}

Designers use prototypes to generate ideas, communicate their ideas, test their ideas, research their ideas and even build theory about their ideas. A critical element of all design projects is the Prototyping phase. Prototypes, therefore, can be results of all such efforts by designers and are highly effective demonstrations of new concepts, design visions or even the first batch of working artifacts. Prototypes are helpful in conducting quick turn-around informal utility and usability checks, formal usability tests and/or market research. Often times done before the actual product or service are developed or manufactured for consumers. Prototyping plays an important role in getting design researchers the data that helps them develop insights into people's lives and to empathize with the people and their living conditions.

Arguably one can say there are two broad paradigms in design research: research for design and research through design. In either case, the word prototype encompasses a vast variety of real or virtual artifacts. For instance, prototypes can be very early design doodles (sketches), low-fidelity paper prototypes, low fidelity software simulations or hardware sketches, high-fidelity (full or partially functioning) software or hardware, and/or provocative (reaction-eliciting) artifacts. Prototypes could even be the first batch of design coming off of manufacturing lines after verification of which parameters are locked down for continuous production. Hence it is useful to describe the prototypes from the perspective of the two research paradigms mentioned above. 
The prototypes that fall under the research for design school of thought are the ones that typically facilitate better design through iterative testing and improvements of design solutions vis-à-vis a user centered design cycle in practice. Prototypes used in such projects are described as Vertical prototypes or Horizontal prototypes. Vertical prototypes emulate fewer features of the final design but go deeper into simulating those features and/or interactions in-depth. Meanwhile, Horizontal prototypes are all about simulating the breadth of features. Consequently, not every feature is simulated in depth and the prototype just provides a look and feel of most features for testing such that iterations are made possible (FALLMAN, 2003).

On the other hand, designers produce prototypes as an investigation unto themselves as well. These types of prototypes fall under the research through design category. Here designers are thinking while doing, doing while thinking and, in general, are expressing ideas through their making or visualization of concepts. This is also known as Thinkering. Research has shown that when given a "Thinkering space" designers can generate and communicate creative ideas in a better way - be it sketches, physical models or visualizations of virtual interactions (MOURA et al, 2009). Prototypes in such investigations are to a) express an idea or a philosophy in an artistic way b) support testing of research hypotheses c) enable study of people's reactions in the form of a provocative probe(s). Prototyping with users and co-creating solutions through participatory design is also another instance of research through design. Participatory prototyping allows inclusion of various stakeholders like managers, engineers, designers, and end-users (LIM, STOLTERMAN and TENENBERG, 2008).

When we combine and think of the kind of prototypes used by both paradigms of design research, the major axes on which the prototypes can vary are quite apparent. The axes are fidelity, familiarity of concept to end users, realism of concept depiction, interactivity allowed with the prototype, and lastly, the number of features emulated. See the figure below for examples of how a prototype can be described using these axes for comparison.

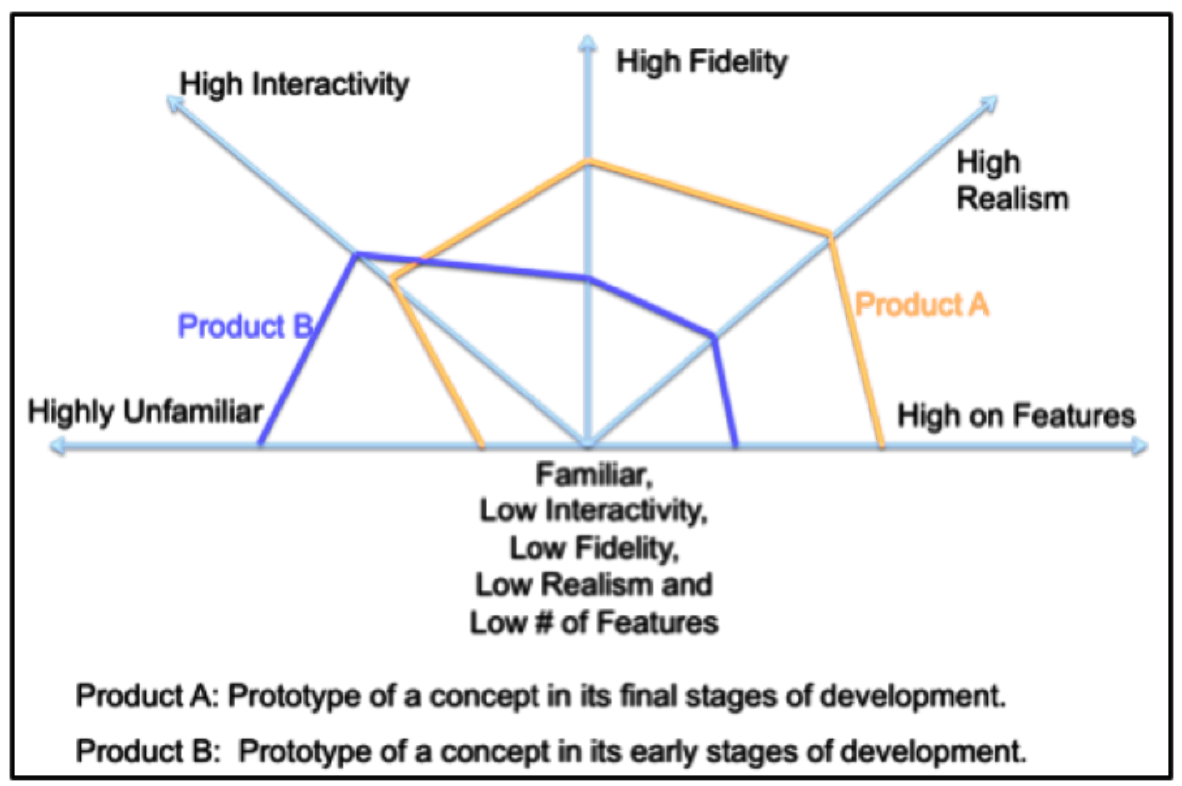

Figure 1. Axes for describing a prototype. Elaborated by the authors.

The roles the prototype plays in design research can also be described along another set of 2 axes: Hypothesis and Concept under development (Figure 2). The term 
hypothesis in this text is used in the meaning of an idea for which evidence for or against can be collected. In the other axes, concept and artifact are used as something that materialize or represent an idea.

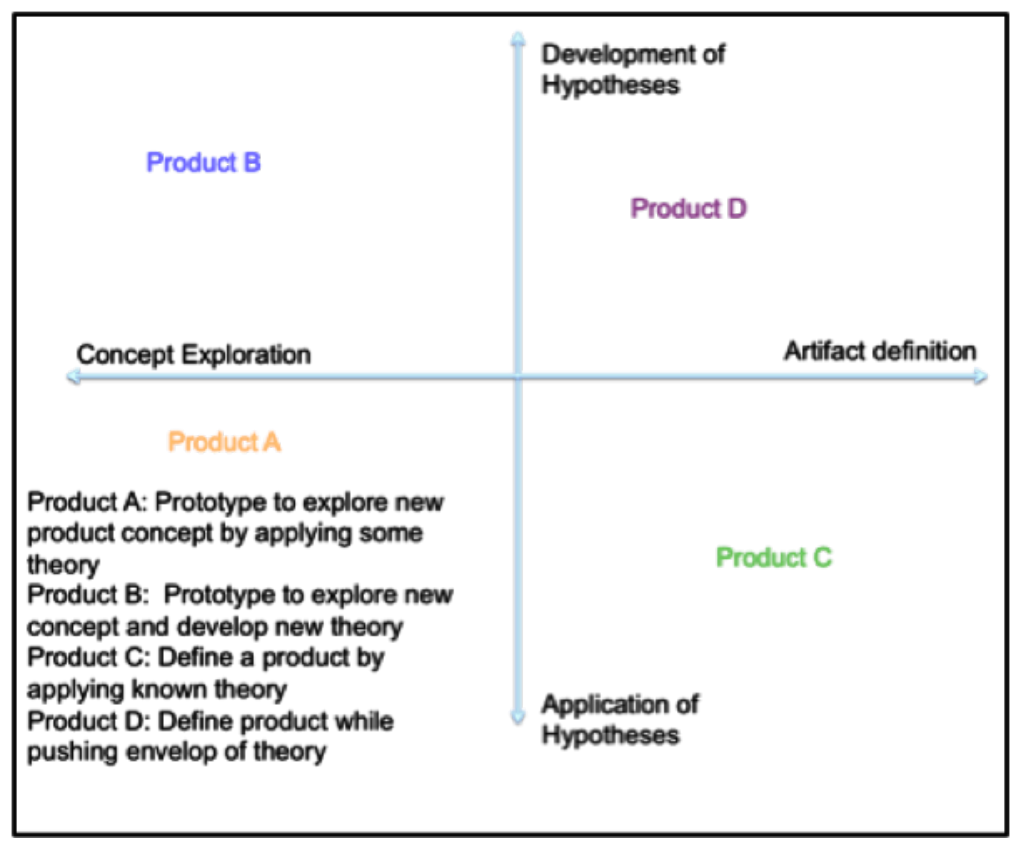

Figure 2. The roles a prototype plays or description of what the prototype is meant to accomplish, using 2 axes of theory and stage of product development. Elaborated by the authors.

In summary, a prototype serves to mediate among people dealing with theories, concepts, and products. A prototype can be used to explore how existing hypotheses may apply to a new concept, or to explore how a new concept can lead to the development of new hypotheses. A prototype can alternatively be used to define a product, either through application of an existing theory or during the process of working toward a new theory.

\section{DESIGN SCENARIOS}

The strategic planning community developed a few decades ago the concept of scenario building as a way to assist organizations in decision-making. In the complex and globalized world we live in, a quick decision can mean the survival or death of a company. In strategic planning, scenario building is predicated on the premise that it is possible to control actions against a partially predictable situation (HEIJDEN, 2005; SCHWARTZ, 1991). Thus, managers will identify potential driving forces that will guide the construction of these possible worlds or scenarios. Perceptible events can help us to immerse ourselves in the pursuit of structural factors that support them. The construction of a scenario does not correspond to a design for a future; instead, it functions as a possible hypothesis. For each hypothesis, an organization will seek to develop alternatives. Scenarios are places where something might happen. Working with highly predictable events, scenario building seeks to identify little determinate elements. Even in the cinema or theater where the scenario represents a fictional world where concrete actors following scripts and speeches act (usually) in a manner that is well-defined, events will occur that are not noticeable or predictable, and the actors must decide how to act at that instant. A warmer and more participatory audience, a technical lighting fault, forgetting a line or uncontrolled laughter of an actor in a scene, may require an immediate and new action. Experienced players are 
accustomed to this type of situation. Scenario planning seeks to tell stories about possible new worlds and plan what action can be taken in these multiple stories. Scenario building also leads us to revise our standards of behavior and mental models. To build different scenarios and "live" in it (as the actor lives a play) we tend to change our present behavior, the way we view our environment today. The process of scenario building as proposed in strategic planning can lead to changes before these worlds come to reality. It is thus a learning process.

It is noticeable how many of the concepts associated with scenario building for the purposes of strategic planning are similar to the concepts related to designing or prototyping. Possible worlds, hypotheses to be validated, uncertainty, and learning are all familiar notions to designers and perhaps for this reason the concept of scenario building was adopted by many design methods. The question that can emerge is about scenarios as possible futures or scenarios as a place to project ourselves into before we return to the brief. The two approaches are not antagonistic, but we believe that in the second one, scenario building is more closely aligned to the design process, as part of the method. Building scenarios as new worlds that can change our mental models could be associated with the concept of research for design, while to build a scenario as part of the project itself could be associated to the notion of research through design.

By way of contrast, in organizations that adopt scenario building in their planning, we can observe that for each different scenario one project will be developed. In case one of these scenarios occurs, the appropriate project plan is ready to be released. In design, however, the goal of scenario building is not usually to generate a different design for each scenario. More commonly, a scenario is seen like visions of a world toward which we want to project. Manzini and Jégou (2006) discuss the concept of Designing-oriented Scenarios (DOS), which can be understood as visions that are motivated and articulated in order to catalyze the energies of the various actors involved in the design process, to generate a common perspective, and hopefully guide their actions in the same direction. The purpose of scenario building in design is not primarily to better control future processes, as is the case in strategic planning. During design, designers seek to take in hand and control elements for the purposes of validation of their ideas. However, before generating these ideas designers proliferate hypotheses. These different hypotheses can be scenarios. Probably the answer is not yes or no but "maybe". This perhaps should be tested in the generation of project ideas or by prototypes. The indefinite aspect of a project or scenario is seen as inherent in the process itself, as something positive and essential. Each design hypothesis can be described using different languages common to designers. Thus, designs, images and text, models and prototypes, can all be used in order to construct narratives that can be associated with discourse.

\section{THE DISCOURSE OF CONSTRUCTION}

As we understand from Foucault, for there to be a persistent category, there needs to be power applied that dynamically protects that category. For our purposes here, the categories are design, prototypes, and scenarios. The boundaries of what constitutes design are patrolled in a kind of "system" by designers, design schools, professional organizations, publications, contests, consultancies, and so on. This system differentiates invention or expression as carried out by designers, whether incremental or transformational/disruptive, from other forms of invention or 
expression such as those produced, for example, by mathematicians, chemists, novelists, or computer scientists. Prototypes, on the other hand, are less carefully demarcated according to professional affiliation, and they can exist across a broader range of activities. It is possible, for instance, to prototype a service or an experience or a piece of software, as well as an object or artifact. Finally, scenarios range even more broadly, from their use not only by designers, but also by futurists, business strategists, the military, economists, and arguably even writers of plays, novels, screenplays, and other forms of fiction.

From the perspective of enforcement of boundaries, the three categories differ, but even the most stringently performed one (design) is subject for some authors at least to a considerable degree of inclusivity. Simon (1969), for instance, famously stated that anyone could be considered a designer who is planning to make a change from the current situation to a preferred situation. The problem with definitions this general is that they run the risk of leaving no room for the defining other, which is to say if everyone falls within the definition, it is not very useful.

Conventionally, we recognize scenarios as a set in which reside prototypes, and both are part of design as a process, as well as its adjacent disciplines. The category above scenarios is comprised of an active, inventive interest in the future and how it is related to the present.

However, it might be more useful to understand scenarios as a superset that contains prototypes, while prototypes contain designs as artifacts, as well as the artifacts created by adjacent disciplines. Scenarios, prototypes, and designs share the characteristic of bridging between the present and the future, neither wholly in one nor the other (Figure 3).

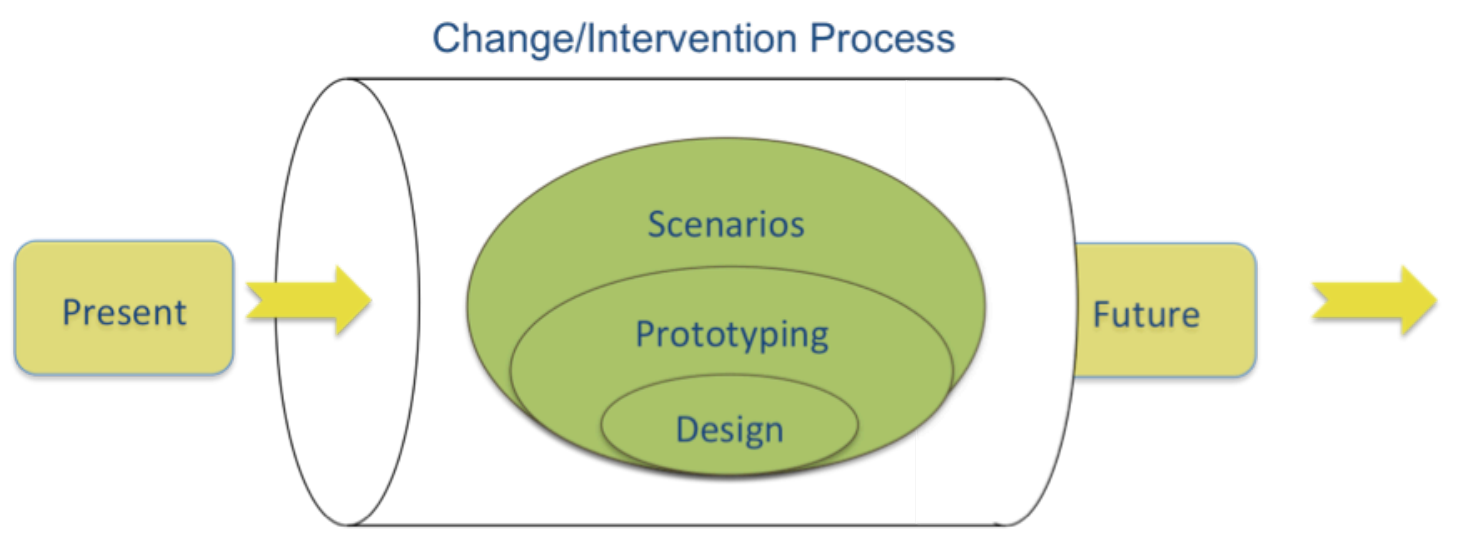

Figure 3: Scenarios, prototypes, and designs as bridges between present and future. Elaborated by the authors.

These 3 categories are not exhaustive. We might, for example, introduce invention and simulation within modeling, with both of them containing scenarios, prototypes, and designs. We could then speak of designs, prototypes, scenarios, and simulations as types of models, while recognizing that not every model is a design, prototype, scenario, or simulation

\section{THE CREATION OF MEANING}

The sub-categories of invention share the feature of having learning as a useful, although not essential, component. They also have a role to play in meaning-making. To design is to create meaning; prototypes, scenarios, and so on are means of carrying out that task. Since meaning is socially constructed, it is a necessary condition of 
meaning-making that it take place in a context of communicational effectiveness, and here again the prototype and the scenario have complementary roles to play. Prototype objects, in the traditional vision of Product Design, are most effective at communicating any number of perceptual aspects such size, weight, shape, texture, and so on. They can establish how functions will be performed. Depending on the nature of the prototype, combined with an understanding of its context of use, it is possible to communicate nearly every feature related to embodiment. What prototypes are less effective at communicating is that understanding of the context of use. A scenario, on the other hand, deprecates embodiment and privileges storytelling about situations where a proposed design can be considered in its future context of use. Prototypes imply people to use them; scenarios explicitly bring forward the people as a means of demonstrating the proposed use, whether in typical, exemplary, or extraordinary situations.

Perhaps more importantly, however, both prototypes and scenarios are strategies for reifying ideas, which is to say giving some kind of form to a concept. There could be several reasons for doing this, but most often it is done for the purpose of communicating it to others and learning more about it. Several question then arise. For instance, to what extent does the prototype or scenario accurately represent the idea under consideration, and to what extent does it either fail outright or else introduce elements that are gratuitous or irrelevant?

A related question is the extent to which a reified idea can actually contribute to a better understanding of the idea itself. There is always a transformation that the idea undergoes in the process, and interacting with an artifact is a substantially different experience from entertaining an idea. However, it is also true that a significant overlap can exist between a core concept and the core concept as instantiated in a prototype or scenario. Perhaps one of the more useful approaches is to frame the concept as a kind of argument for which the prototype or scenario is a type of evidence (GALEY and RUECKER, 2010). In this case, it may be possible to set aside information gathered concerning the irrelevant or misleading features of the prototype, and focus instead only on the evidence that is related to the argument being made.

A possible danger of this approach is that the exercise can turn into one of strengthening a foregone conclusion rather than attempting to learn anything new. Another pitfall is the tendency to treat the insights gained as applying only to the prototype or scenario, and not to the larger idea of which the current instance is one form of reification. Since it is possible to embody an idea in any number of ways, the best approach may be to choose a small set of them, and provide people an opportunity for comparison (TOHIDI, et al. 2006).

Setting aside for a moment the role of prototypes and scenarios in user studies, a more general interpretation is that they can serve the function of mediating objects (e.g. LATOUR, 1988), where the purpose of the objects does involve information, but is primarily focused on the exchanges among people. The change in focus is also an expansion, since a reified idea is not necessarily deployed as a means of communication, nor is the designer's creation of meaning necessarily concerned with communicative goals such as simplicity and clarity, since other concerns may have taken priority. 


\section{CONCLUSION}

We have argued for a conceptual nesting of designs within prototypes, prototypes within scenarios, and scenarios within invention. This interpretation has consequences for our understanding, not just of the nouns, but also the verbs: of design, designing, prototypes, prototyping, scenarios, scenario writing, inventions, and inventing as potential means of knowledge production. Within our proposed system, design and designing are the most constrained, while scenarios and scenario writing have more freedom. It is possible, for instance to write a scenario about a situation where a working design would currently be impossible. For example, we can talk about a space elevator, created by dropping a 60-mile-long rope from a geostationary satellite down to earth, but we don't currently have a material to make the rope. None of our materials are strong enough and light enough to support their own weight. We could, however, prototype this kind of object by creating a sketch or scale model.

The implication for design practice is that it could be logically extended, not necessarily through claiming, as Simon did, all of invention, but instead through looking into adjacencies at the various levels and offering strategies both for the development of more design-specific approaches, and for ways that the design-specific approaches already in place can contribute beyond design. This is essentially a political suggestion about the possible place of design in the world, and how we might begin to take practical steps to work in a larger arena, closer to the one claimed within the bounds of discourse established by Herbert Simon over 45 years ago.

\section{REFERENCES}

FALLMAN, Daniel. Design-oriented human-computer interaction. Proceedings of the SIGCHI Conference on Human factors in computing systems, New York:ACM, 2003.

FOUCAULT, Michel. The Archeology of Knowledge. Transl. A. M. Sheridan Smith. New York:Routledge Classics, 2004.

HEIJDEN, Kees van der. Scenarios: The Art of Strategic Conversation. West Sussex:John Willey \& Sons, 2005.

GALEY, Alan, RUECKER, Stan and The INKE Research Group. How a Prototype Argues. In: Literary and Linguistic Computing. 25(3), 2010.

LATOUR, Bruno. Mixing Humans and Nonhumans Together: The Sociology of a DoorCloser. In: Social Problems, Vol. 35, No. 3, Special Issue: The Sociology of Science and Technology, 1988, 298-310.

YOUN-KYUNG, Lim, STOLTERMAN, Erik, and TENENBERG Josh. The anatomy of prototypes: Prototypes as filters, prototypes as manifestations of design ideas. In: ACM Transactions on Computer-Human Interaction, TOCHI 15.2, 2008.

MANZINI, Ezio. and JÉGOU, François. Design degli scenari. In: BERTOLA, P.; MANZINI, E. Design Multiverso Appunti di fenomenologia del design. Milano: Edizioni POLI.design, 2006, 189-207.

MOURA, H., FAHNSTROM, D., PRYGROCKI, G., and MCLEISH, T. J. Thinkeringspace: Designing for Collaboration. In: Visible Language, v43, n1, 2009, 46-61.

SIMON, Herbert A. The Sciences of Artificial. Cambridge:MIT, 1969. 
SCHWARTZ, Peter. The Art of the Long View. New York:Doubleday, 1991.

MARYAM, Tohidi, BUXTON, William, BAECKER, Ronald, and SELLEN, Abigail. Getting the right design and the design right. In: Proceedings of the SIGCHI Conference on Human Factors in Computing Systems, ACM:New York, 2006. 